\title{
Outcomes after transplantation for "failed" Fontan: A single-institution experience
}

\author{
Ryan R. Davies, MD, ${ }^{a}$ Robert A. Sorabella, MD, ${ }^{\mathrm{b}}$ Jonathan Yang, MD, ${ }^{\mathrm{b}}$ Ralph S. Mosca, MD, ${ }^{\mathrm{c}}$ \\ Jonathan M. Chen, MD, ${ }^{\mathrm{d}}$ and Jan M. Quaegebeur, MD, $\mathrm{PhD}^{\mathrm{b}}$
}

\begin{abstract}
Objective: Despite the excellent outcomes in the current era after the Fontan procedure, it continues to have an inherent risk of failure. Cardiac transplantation provides 1 option for treating these patients; however, the indications for, timing of, and outcomes after, transplantation remain undefined. We examined our own institutional experience with transplantation for failed Fontan.
\end{abstract}

Methods: The records of 155 patients transplanted for congenital heart disease at a single institution from June 1984 to September 2007 were reviewed. Of these patients, 43 had undergone a previous Fontan procedure (25 male, 15 female; median age, 14.5 years; range, 1-47; 23 classic Fontan, 13 lateral tunnel, 4 extracardiac conduit, and 3 revised to shunt). The predictors of short- and long-term survival were evaluated, and the Fontan patients were compared with all other patients with congenital heart disease $(n=129,78$ male, 51 female).

Results: The most common indications for transplantation included protein-losing enteropathy (PLE) (39.5\%), chronic heart failure $(41.8 \%)$, and acute post-Fontan failure $(9.3 \%)$. The transplants performed in Fontan patients were more likely to require pulmonary artery reconstruction $(85.4 \%$ vs $42.9 \% ; P<.0001)$ and had longer cardiopulmonary bypass times ( 278 vs 179 minutes; $P<.0001)$. The 90 -day mortality rate was greater in the Fontan group $(35.0 \%$ vs $20.0 \% ; P=.055)$. No correlation was observed between the interval from Fontan to transplantation and morality; however, renal failure was a strong predictor of early mortality (odds ratio, $10.8 ; 95 \%$ confidence interval, $1.5-75.7)$.

Conclusions: Transplantation is an acceptable treatment for patients with a failed Fontan. Clinical factors (instead of the indication for transplantation) appear to have the greatest correlation with early mortality. (J Thorac Cardiovasc Surg 2012;143:1183-92)

Supplemental material is available online.

In 1971, Fontan first described placing the systemic and pulmonary circulations in series as a treatment for tricuspid atresia. ${ }^{1}$ Since then, the use of the Fontan procedure has been expanded to include a variety of congenital heart defects in which 2 functional ventricles cannot be constructed. Despite the extraordinary advances that the Fontan procedure and its modifications represent in the care of children with single ventricle lesions, there has always been an

\footnotetext{
From the Nemours Cardiac Center, ${ }^{\text {a }}$ A.I. duPont Hospital for Children, Wilmington,

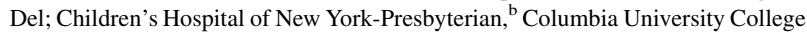
of Physicians and Surgeons, New York, NY; New York University Langone Medical Center, ${ }^{\mathrm{c}}$ New York, NY; and Joan and Sanford Weill Medical College of Cornell University, ${ }^{\mathrm{d}}$ New York, NY.

Disclosures: Authors have nothing to disclose with regard to commercial support.

Received for publication April 19, 2011; revisions received Sept 23, 2011; accepted for publication Dec 14, 2011.

Address for reprints: Ryan R. Davies, MD, Nemours Cardiac Center, A.I. duPont Hospital for Children, 1600 Rockland Rd, Wilmington, DE 19803 (E-mail: rdavies@nemours.org).

$0022-5223 / \$ 36.00$

Copyright $(2012$ Published by Elsevier Inc. on behalf of The American Association for Thoracic Surgery

doi:10.1016/j.jtcvs.2011.12.039
}

ongoing concern about the long-term future of the circulation driven by a single ventricle., ${ }^{2,3}$ More recent examinations of post-Fontan outcomes have confirmed the long-term challenges facing these patients in the early and late postoperative period. 4

A range of other pathologic processes (often incompletely understood) can result in progressive morbidity and mortality after the Fontan procedure, including Fontan circuit failure with normal ventricular function, severe growth retardation, intractable arrhythmias, PLE, thrombotic circuit occlusion, pulmonary arteriovenous malformations, and, rarely, acute post-Fontan failure. Although some of these pathologic features might be amenable to Fontan revision, especially where correctable anatomic problems or focal atrial arrhythmias predominate, cardiac transplantation often provides the only real alternative for these patients. Accordingly, we chose to examine our own experience with cardiac transplantation after failed Fontan to examine the outcomes and identify the predictors of early and late post-transplant mortality.

\section{METHODS \\ Patient Population}

A retrospective review was performed to identify all patients (both adult and pediatric) undergoing primary cardiac transplantation at the Columbia 


\section{Abbreviations and Acronyms \\ $\mathrm{CHD}=$ congenital heart disease \\ $\mathrm{CI}=$ confidence interval}

University Medical Center from January 1, 1984, to January 1, 2007. The institutional review board for Columbia University Medical Center approved the study, and the requirement for informed consent was waived. A total of 172 patients with congenital heart disease (CHD) underwent transplantation within the study period. Among the patients with CHD, $43(25.0 \%)$ had undergone a previous Fontan operation; these patients formed the basis for the present analysis.

\section{Surgical Technique}

Because of the potential need for extensive recipient reconstruction, the margins of donor tissue excised were extended, usually to include the aortic arch and proximal head vessels, branch pulmonary arteries to the hilum, and superior vena cava and innominate vein. The preferred method of graft preservation was a single dose of cold Celsior solution (Genzyme Corporation, Cambridge, Mass) given by pressurized infusion into the aortic root. Heart transplantation was performed under hypothermic cardiopulmonary bypass, with deep hypothermic circulatory arrest as needed. Arterial cannulation was preferentially performed in the aorta, with bicaval venous cannulation; groin cannulation was used as necessary. In the early part of the series, the biatrial anastomosis (as described by Lower and Shumway ${ }^{5}$ ) was used in most patients, but in more recent patients, with the demonstration of its several advantages, ${ }^{6}$ the bicaval technique has been preferred, except in cases in which anatomic considerations preclude its use. ${ }^{7}$

\section{Data Collection}

A hospital chart review was conducted for each identified patient and their donor, and the data were entered into a computerized database. The donor and recipient demographic and intraoperative and postoperative variables were acquired. The follow-up period for the patients with failed Fontan circulation ranged from 0.4 to 19.5 years (median, 30.7 months; mean, 52.5). The survival data were cross-referenced with the Social Security Master Death Index (available at: http://www.ssdi.rootsweb.ancestry.com).

\section{Statistical Analysis}

Univariate and multivariate statistical methods were used to identify and estimate the risk factors for all-cause mortality and 30-, 60-, and 90-day mortality. In addition, the study population was compared (using similar techniques) with all other patients with CHD and with all non-CHD patients who underwent transplantation during the same period.

The methods of statistical analysis included the chi-square test for comparisons of dichotomous risk factors with negative outcomes, the MantelHaenszel chi-square test for comparisons taking into consideration disease severity, and the Wilcoxon test for comparisons of continuous variables with negative outcomes $(P<.05)$. Life-table estimates (Kaplan-Meier) were calculated using the LIFETEST procedure of SAS, version 9.13, for Windows (SAS Institute, Cary, NC) with the log-rank test for differences between strata.

\section{RESULTS}

\section{Baseline Demographics and Clinical Condition at Transplantation}

Fewer patients were younger than 5 years $(9.3 \%$ vs $36.4 \%, P=.0007)$ in the Fontan group than in the group of other patients with $\mathrm{CHD}$, although the mean age was similar between the 2 groups ( 15.8 vs 13.7 years, $P=.3$ ). Patient gender and the indicators of clinical condition at transplantation did not differ significantly between the 2 groups (Table 1). Both groups had a high incidence of previous sternotomy, and single ventricle diagnoses were more common among the Fontan patients (Table 1). The Fontan patients had lower albumin levels in the week before transplantation (3.7 vs 4.0, $P=.02$ ). Among the patients with a previous Fontan operation, the Fontan circuit was a classic (atriopulmonary connection) Fontan in 23 patients $(53.5 \%)$, a lateral tunnel in $13(30.2 \%)$, an extracardiac connection in $4(9.3 \%)$, and had been taken down in 3 (7.0\%; Table 2).

\section{Previous Surgical Interventions}

Of all 172 patients undergoing transplantation for CHD, $72(41.8 \%)$ had a single ventricle. Of these 72 patients, 5 $(6.9 \%)$ had undergone no previous palliation, $10(13.9 \%)$ had had only a shunt placed, $14(19.4 \%)$ had undergone a classic or bidirectional Glenn procedure but no Fontan procedure, and $43(59.7 \%)$ had undergone the Fontan procedure.

The median age at Fontan completion was 5.4 years (mean, 7.4; range, 1-25). Nine patients (20.9\%) underwent the Fontan procedure at our institution (Table 3); the remainder were referred for transplant evaluation after a Fontan procedure at other institutions. The mean interval from the initial Fontan operation to transplantation was 8.6 years (range, 6 days to 24.5 years).

\section{Hemodynamics}

The mean pretransplant transpulmonary gradient was 7.0 $\mathrm{mm} \mathrm{Hg}$, with a mean Fontan conduit pressure of $18.4 \mathrm{~mm}$ $\mathrm{Hg}$ (range, 13-25 $\mathrm{mm} \mathrm{Hg}$ ). In the setting of extensive aortopulmonary collateral flow, the pulmonary vascular resistance could not be calculated reliably.

\section{Transplant Procedure and Operative Technique}

The number of days on the waiting list was similar for both groups (Fontan, 56.9 vs non-Fontan, 63.5 days; $P=.8)$. Femoral arterial and venous cannulation was required in 16 Fontan patients (37.2\%). Most other patients had bicaval venous and aortic arterial cannulations. Rarely used cannulation sites included the subclavian artery or carotid artery and the axillary vein or an extracardiac conduit. Fontan patients were more likely to require pulmonary artery reconstruction $(85.4 \%$ vs $42.9 \%, P<.0001)$, although the need for reconstruction of the venous return $(19.5 \%$ vs $17.7 \%, P=.8)$ or transplantation to a single lung ( $4.9 \%$ vs $8.0 \%, P=.5$ ) was similar (Table E1). Most commonly, the recipient pulmonary artery bifurcation or right pulmonary artery required reconstruction. Repair of venous return was most commonly required because of the presence of a left superior vena cava. Donor tissue (either pulmonary 
TABLE 1. Baseline demographics among 43 patients with "failed Fontan" compared with all other transplants for congenital heart disease $(\mathbf{n}=129)^{*}$

\begin{tabular}{|c|c|c|c|}
\hline Demographic & $\begin{array}{l}\text { Fontan } \\
(n=43)\end{array}$ & $\begin{array}{c}\text { Other CHD } \\
(n=129)\end{array}$ & $\begin{array}{c}P \\
\text { value }\end{array}$ \\
\hline Gender (male) & $28(65.1 \%)$ & $78(65.1 \%)$ & .59 \\
\hline \multicolumn{4}{|l|}{ Blood type } \\
\hline A & $19(46.3 \%)$ & $49(41.5 \%)$ & .4 \\
\hline $\mathrm{AB}$ & $4(9.6 \%)$ & $6(5.1 \%)$ & \\
\hline B & $2(4.9 \%)$ & $12(10.2 \%)$ & \\
\hline $\mathrm{O}$ & $16(39.1 \%)$ & $51(42.2 \%)$ & \\
\hline \multicolumn{4}{|l|}{ Diagnosis } \\
\hline Single ventricle & $43(100.0 \%)$ & $29(22.6 \%)$ & $<.0001 \dagger$ \\
\hline $\begin{array}{l}\text { Transposition of the great } \\
\text { arteries }\end{array}$ & $8(18.6 \%)$ & $28(22.1 \%)$ & .6 \\
\hline Tetralogy of Fallot & $1(3.3 \%)$ & $15(15.2 \%)$ & .09 \\
\hline Pulmonary atresia & $4(13.3 \%)$ & $22(22.0 \%)$ & .3 \\
\hline Pulmonary stenosis & $12(38.7 \%)$ & $19(19.6 \%)$ & $.03 \dagger$ \\
\hline $\begin{array}{l}\text { Hypoplastic left heart } \\
\text { syndrome }\end{array}$ & $6(14.6 \%)$ & $18(15.4 \%)$ & .9 \\
\hline Tricuspid atresia & $11(26.8 \%)$ & $2(1.6 \%)$ & $<.0001 \dagger$ \\
\hline \multicolumn{4}{|l|}{ Surgical history } \\
\hline Previous sternotomy & $43(100.0 \%)$ & $96(74.4 \%)$ & $.0002 \dagger$ \\
\hline Aortopulmonary shunt $\ddagger$ & $31(72.3 \%)$ & $80(62.0 \%)$ & .2 \\
\hline Classic or bidirectional Glenn & $19(44.2 \%)$ & $22(17.1 \%)$ & $.0003 \dagger$ \\
\hline Both Glenn and shunt & $16(37.2 \%)$ & $18(14.0 \%)$ & $.0009 \dagger$ \\
\hline Hemi-Fontan & $2(4.9 \%)$ & $0(0.0 \%)$ & $.02 \dagger$ \\
\hline \multicolumn{4}{|l|}{ Clinical condition } \\
\hline Hospitalized & $21(60.0 \%)$ & $53(64.6 \%)$ & .6 \\
\hline Intensive care unit & $14(40.0 \%)$ & $29(35.4 \%)$ & .6 \\
\hline Mechanical ventilation & $7(20.0 \%)$ & $19(21.4 \%)$ & .9 \\
\hline Creatinine $>1.5$ & $6(15.8 \%)$ & $6(14.6 \%)$ & .9 \\
\hline Ventricular assist device & $0(0.0 \%)$ & $1(0.9 \%)$ & .5 \\
\hline $\begin{array}{l}\text { Extracorporeal membrane } \\
\text { oxygenation }\end{array}$ & $5(12.8 \%)$ & $5(4.7 \%)$ & .08 \\
\hline
\end{tabular}

*Percentages indicate percentage of patients with a risk factor among those for whom data were available for that risk factor. †Statistically significant. †̇Including BlalockTaussig shunts and other surgical systemic-to-pulmonary shunts.

arterial or innominate venous tissue) was the most common material used for reconstruction, although bovine or pericardial patches were also used, as was atrial tissue (Table E1). One patient with situs inversus required interatrial baffles to direct left-sided venous return to the donor right atrium. Baffles were also used to redirect totally anomalous pulmonary venous return into the donor left atrium in another case.

The cardiopulmonary bypass times (mean, 278 vs 179 minutes; $P<.0001)$ and aortic cross-clamp times (mean, 104 vs 81 minutes; $P=.09$ ) were longer in the Fontan group. The total donor organ ischemic times were slightly longer in the Fontan group (258 vs 226 minutes, $P=.04)$. Twelve patients $(27.9 \%)$ in the Fontan group required a period of circulatory arrest (Table E1), and a trend was seen toward longer circulatory arrest times compared with the circulatory arrest required in the other patients with CHD (mean, 50.3 vs 26.1 minutes; $P=.09$ ).

\section{Early Post-Transplant Outcomes}

Morbidity. Neurologic events occurred in 8 patients in the Fontan group, including seizures in 1, strokes in 6, and a subdural hemotoma in 1 patient (Table E2). Two of the patients with stroke $(33.3 \%)$ died before hospital discharge. In both cases, the stroke was likely related to cardiac arrest, hypotension, and cerebral hypoxia. Of the other 4 patients, 1 had severe congenital cerebrovascular anomalies identified in the postoperative period. The other 3 appeared to have hypoxic/ischemic strokes related to postoperative hypotension or cardiac arrest.

Five patients $(11.6 \%)$ in the Fontan group required dialysis in the postoperative period (Table E3). Only 1 of these patients had preoperative renal dysfunction, most had complicated postoperative courses, including sepsis and multiorgan system failure. All 5 patients died before discharge. Six patients $(14.0 \%)$ required reoperations for bleeding; the inhospital mortality within this group was 50\%. Drug-treated infections (including pneumonia, septicemia, and urinary tract infections) occurred in 21 patients $(48.8 \%)$. Of these patients, 7 (33.3\%) died within 90 days of transplantation. Neither postoperative ( 32.9 vs 28.1 days, $P=.52$ ) nor total (46.4 vs 58.4 days, $P=.25$ ) length of stay differed between the Fontan and non-Fontan CHD groups.

Mortality. Trends were seen toward increased mortality in the Fontan group at 30 days $(25.0 \%$ vs $15.6 \%, P=.16)$ and 60 days $(27.5 \%$ vs $18.3 \%, P=.21)$ but these did not reach statistical significance. The 90-day mortality rate was greater among patients in the Fontan group than among the other patients with CHD $(35.0 \%$ vs $20.0 \%, P=.055$; odds ratio $[\mathrm{OR}], 2.15 ; 95 \%$ confidence interval [CI], 0.97-4.76), although this was primarily the result of the high mortality early in our experience (before 2000; $40.9 \%$ vs $18.9 \%, P=.046)$. Patients with "failed Fontan" who had undergone transplanted after 1999 had similar mortality to those with other forms of CHD $(27.8 \%$ vs $22.2 \%, P=.64)$. In this later group, early mortality occurred entirely among the adult patients (Table 4).

Among the non-Fontan patients, the univariate predictors of 30-day mortality included female gender (OR, 3.3; 95\% CI, 1.2-9.5), age younger than 1 year (OR, 4.1; 95\% CI, 1.4-12.5), hospitalization at transplantation (OR, 4.5; 95\% CI, 0.5-38.9), the need for extracorporeal membrane oxygenation (OR, 15.4; 95\% CI, 1.5-158.2), pretransplant need for mechanical ventilation (OR, 6.8; 95\% CI, 1.924.4), history of aortopulmonary shunt without a subsequent Glenn procedure (OR, 2.7; 95\% CI, 0.9-8.4), and a diagnosis of tetralogy of Fallot (OR, 3.6; 95\% CI, 1.0-12.8).

Similar factors were important among the patients in the Fontan group (although the sample size limited the power of the analyses): hospitalization $(0.0 \%$ vs $28.6 \%, P=.0492)$, 
TABLE 2. Patients undergoing transplantation after a "failed Fontan" procedure

\begin{tabular}{|c|c|c|c|c|c|c|c|c|}
\hline $\begin{array}{l}\text { Pt. } \\
\text { no. }\end{array}$ & Fontan type & Gender & $\begin{array}{l}\text { Age at } \\
\text { Fontan }\end{array}$ & $\begin{array}{c}\text { Age at } \\
\text { transplantation } \\
(\mathrm{yr})\end{array}$ & $\begin{array}{c}\text { Transplantation } \\
\text { year }\end{array}$ & Indication & Outcome & Cause of death \\
\hline 39 & Classic & M & $? ?$ & 16 & 1989 & Chronic failure & Died, $16 \mathrm{yr}$ & Chronic rejection \\
\hline 49 & Classic & M & $3 y$ & 21 & 1990 & PLE & Alive & \\
\hline 53 & Classic & M & $4 y$ & 15 & 1990 & PLE & Died, POD 30 & Sepsis and ARDS \\
\hline 69 & $\begin{array}{l}\text { Classic } \\
\quad \text { (fenestrated) }\end{array}$ & M & $10 \mathrm{y}$ & 15 & 1992 & PLE & Alive & \\
\hline 73 & Take-down & $\mathrm{F}$ & $5 \mathrm{y}$ & 15 & 1992 & Chronic failure & Died, POD 0 & Primary failure \\
\hline 81 & Classic & M & $2 y$ & 10 & 1992 & Chronic failure & Alive & \\
\hline 82 & Lateral tunnel & M & $3 y$ & 3 & 1992 & Acute failure & Died, POD 1 & Bleeding \\
\hline 83 & Classic & M & $16 \mathrm{y}$ & 16 & 1992 & Chronic failure & Died, 5 yr & Chronic rejection \\
\hline 787 & Classic & M & $10 \mathrm{y}$ & 26 & 1992 & Chronic failure & Alive & \\
\hline 790 & Classic & M & $13 \mathrm{y}$ & 23 & 1992 & Chronic failure & Died, POD 1 & Bleeding \\
\hline 87 & Classic & $\mathrm{F}$ & $5 \mathrm{y}$ & 18 & 1993 & Pulmonary AVM & Alive & \\
\hline 791 & Classic & M & $14 \mathrm{y}$ & 20 & 1993 & PLE & Died, 14 yr & Chronic rejection \\
\hline 91 & $\begin{array}{l}\text { Lateral tunnel } \\
\quad \text { (fenestrated) }\end{array}$ & M & $1 \mathrm{y}, 1 \mathrm{mo}$ & 1 & 1994 & Acute failure & Alive & \\
\hline 98 & Classic & M & $1 \mathrm{y}, 11 \mathrm{mo}$ & 11 & 1994 & PLE & Died, POD 2 & Bleeding \\
\hline 99 & Classic & M & 7 & 12 & 1994 & Chronic failure & Died, 6 wk & Stroke \\
\hline 379 & Lateral tunnel & $\mathrm{F}$ & 5 & 20 & 1994 & Chronic failure & Died, POD 0 & Bleeding \\
\hline 794 & Classic & M & 10 & 26 & 1994 & Chronic failure & Died, 7 yr & Chronic rejection \\
\hline 105 & Classic & $\mathrm{F}$ & 3 & 8 & 1995 & PLE & Alive & \\
\hline 113 & $\begin{array}{l}\text { Classic } \\
\quad \text { (fenestrated) }\end{array}$ & $\mathrm{F}$ & $1 \mathrm{y}, 8 \mathrm{mo}$ & 8 & 1995 & PLE & Died, 6 yr & Chronic rejection \\
\hline 115 & Lateral tunnel & M & $15 \mathrm{y}$ & 16 & 1995 & Chronic failure & Alive & \\
\hline 145 & $\begin{array}{l}\text { Classic } \\
\quad \text { (fenestrated) }\end{array}$ & $\mathrm{F}$ & $6 y$ & 7 & 1998 & Chronic failure & Died, POD 0 & Bleeding \\
\hline 155 & Classic & M & $2 \mathrm{y}$ & 12 & 1998 & Chronic failure & Alive & \\
\hline 801 & Lateral tunnel & $\mathrm{F}$ & $18 \mathrm{y}$ & 31 & 1998 & PLE & Died, POD 8 & Sepsis \\
\hline 171 & Classic & $\mathrm{F}$ & $12 \mathrm{y}$ & 23 & 2000 & PLE & Alive & \\
\hline 198 & Lateral tunnel & M & $2 y$ & 7 & 2002 & Chronic failure & Alive & \\
\hline 203 & Taken-down & $\mathrm{F}$ & $2 \mathrm{y}$ & 2 & 2003 & Acute failure & Alive & \\
\hline 204 & Classic & M & $2 \mathrm{y}$ & 13 & 2003 & Chronic failure & Alive & \\
\hline 205 & Take-down & $\mathrm{F}$ & $2 \mathrm{y}$ & 7 & 2003 & Pulmonary AVM & Alive & \\
\hline 207 & Lateral tunnel & M & $3 y$ & 9 & 2003 & Plastic bronchitis & Alive & \\
\hline 234 & $\begin{array}{l}\text { Lateral tunnel } \\
\text { (fenestrated) }\end{array}$ & $\mathrm{F}$ & $9 \mathrm{y}$ & 9 & 2004 & Chronic failure & Alive & \\
\hline 768 & Classic & M & $10 \mathrm{y}$ & 31 & 2004 & PLE & Alive & \\
\hline 248 & $\begin{array}{l}\text { Lateral tunnel } \\
\quad \text { (fenestrated) }\end{array}$ & M & $15 \mathrm{y}$ & 16 & 2005 & PLE & Died, $10 \mathrm{wk}$ & Sepsis \\
\hline 249 & Extracardiac & $\mathrm{F}$ & $9 y$ & 13 & 2005 & PLE & Died, 8 wk & Sepsis \\
\hline 251 & Extracardiac & M & $5 \mathrm{y}$ & 19 & 2005 & Acute failure & Died, POD 0 & Hyperkalemic arres \\
\hline 258 & $\begin{array}{l}\text { Lateral tunnel } \\
\quad \text { (fenestrated) }\end{array}$ & M & $3 y$ & 3 & 2005 & Chronic failure & Alive & \\
\hline 261 & Classic & $\mathrm{F}$ & $4 y$ & 22 & 2005 & PLE & Died, 8 wk & Sepsis \\
\hline 510 & $\begin{array}{l}\text { Extracardiac } \\
\quad \text { (fenestrated) }\end{array}$ & $\mathrm{F}$ & $2 \mathrm{y}$ & 8 & 2006 & PLE & Alive & \\
\hline 726 & Lateral tunnel & $\mathrm{F}$ & $2 \mathrm{y}$ & 10 & 2006 & Pulmonary AVM & Died, 4 mo & Acute rejection \\
\hline 740 & $\begin{array}{l}\text { Extracardiac } \\
\quad(\text { fenestrated) }\end{array}$ & M & $1 \mathrm{y}, 6 \mathrm{mo}$ & 15 & 2006 & PLE & Alive & \\
\hline 772 & Classic & M & $25 \mathrm{y}$ & 47 & 2006 & Chronic failure & Alive & \\
\hline 757 & Classic & M & $14 \mathrm{y}$ & 38 & 2007 & PLE & Died, POD 1 & Bleeding \\
\hline 844 & Lateral tunnel & M & $2 \mathrm{y}$ & 13 & 2008 & PLE & Alive & \\
\hline 866 & Lateral tunnel & $\mathrm{M}$ & $2 \mathrm{y}$ & 13 & 2009 & Chronic failure & Alive & \\
\hline
\end{tabular}


TABLE 3. Details of Fontan procedure among patients who underwent Fontan procedure

\begin{tabular}{|c|c|c|c|c|}
\hline $\begin{array}{l}\text { Pt. } \\
\text { no. }\end{array}$ & Year & Diagnosis & Previous procedures & Clinical course \\
\hline 82 & 1992 & DILV with L AV valve atresia, L TGA & Pulmonary banding & $\begin{array}{l}\text { Postoperative ventricular failure requiring } \\
\text { ECMO implantation, transplant } 9 \mathrm{~d} \text { later }\end{array}$ \\
\hline 91 & 1994 & DORV with interrupted aortic arch & Pulmonary banding & $\begin{array}{l}\text { Postoperative ventricular failure requiring } \\
\text { ECMO implantation, transplant } 6 \mathrm{~d} \text { later }\end{array}$ \\
\hline 115 & 1995 & Single ventricle with single AV canal, PS & None & $\begin{array}{l}\text { Developed AV valve incompetence requiring } \\
\text { mechanical valve replacement within } 2 \text { mo, } \\
\text { progressively worsening cardiac function, } \\
\text { transplant within } 6 \text { mo }\end{array}$ \\
\hline 198 & 1997 & Tricuspid atresia, VSD & Pulmonary banding & $\begin{array}{l}\text { Long-term development of dilated } \\
\text { cardiomyopathy, transplanted } 5 \text { y later }\end{array}$ \\
\hline 234 & 2004 & $\begin{array}{l}\text { Unbalanced AV canal with aortic atresia, } \\
\text { hypoplastic left heart }\end{array}$ & $\begin{array}{l}\text { Norwood with central shunt, } \\
\text { BDG w/pulmonary arterioplasty }\end{array}$ & $\begin{array}{l}\text { Fontan procedure included AV valve } \\
\text { annuloplasty and patch enlargement of the L } \\
\text { PA, developed worsening AV valve } \\
\text { regurgitation, high PA pressures, thrombus in } \\
\text { conduit, transplanted approximately } 6 \mathrm{wk} \text { later }\end{array}$ \\
\hline 248 & 1992 & $\begin{array}{l}\text { Dextrocardia, DORV, common atrium, PS, } \\
\text { TGA, TAPVR }\end{array}$ & Central shunt, repair of TAPVR & $\begin{array}{l}\text { Uncomplicated, developed PLE, transplanted } 13 \\
\text { yr later }\end{array}$ \\
\hline 768 & 1983 & DILV & Pulmonary banding & $\begin{array}{l}\text { Uncomplicated, developed PLE, transplanted } 19 \\
\text { yr later }\end{array}$ \\
\hline 844 & 1997 & HLHS & Norwood stage $1, \mathrm{BDG}$ & $\begin{array}{l}\text { Uncomplicated, developed PLE, systemic- } \\
\text { pulmonary collaterals causing hemoptysis, } \\
\text { transplanted } 11 \text { years later }\end{array}$ \\
\hline 866 & 1997 & HLHS & Norwood stage $1, \mathrm{BDG}$ & $\begin{array}{l}\text { Fontan procedure complicated by coagulopathy, } \\
\text { massive epistaxis, and eventual hypotensive } \\
\text { cardiac arrest approximately } 1 \mathrm{wk} \\
\text { postoperatively, then a prolonged chylothorax; } \\
\text { subsequent course was uncomplicated until } \\
\text { development of chronic heart failure, } \\
\text { transplanted } 12 \mathrm{yr} \text { later }\end{array}$ \\
\hline
\end{tabular}

Pt. No., Patient number; $D I L V$, double inlet left ventricle; $L$, left; $A V$, atrioventricular; $T G A$, transposition of the great arteries; $E C M O$, extracorporeal membrane oxygenation; $D O R V$, double outlet right ventricle; $P S$, pulmonary stenosis; $V S D$, ventricular septal defect; $B D G$, bidirectional Glenn; $P A$, pulmonary atresia; TAPVR, totally anomalous pulmonary venous return; HLHS, hypoplastic heart syndrome.

extracorporeal membrane oxygenation (OR, 5.6; 95\% CI, $0.8-40.1)$, and previous shunt without a Glenn procedure (OR, 4.3; 95\% CI, 0.8-22.5). However, gender was not a significant predictor of poor outcomes (OR, 1.14;95\% CI, 0.3-5.0). In addition, a creatinine level greater than 1.5 was also associated with greater early mortality (OR,

TABLE 4. Mortality by era of transplantation (among Fontan patients, $n=43$ )

\begin{tabular}{lrcr}
\hline Mortality & Before 1999 & After 1999 & $\boldsymbol{P}$ value \\
\hline $30-\mathrm{d}$ & $8 / 23(34.8 \%)$ & $2 / 20(10.0 \%)$ & .0550 \\
$\mathrm{Age}<18$ y & $5 / 16(31.3 \%)$ & $0 / 14(0.0 \%)^{*}$ & \\
$\mathrm{Age} \geq 18$ y & $3 / 7(42.9 \%)$ & $2 / 6(33.3 \%)^{*}$ & \\
$60-\mathrm{d}$ & $9 / 23(39.1 \%)$ & $2 / 20(10.0 \%)$ & .0290 \\
$\mathrm{Age}<18$ y & $6 / 16(37.5 \%)$ & $0 / 14(0.0 \%)^{*}$ & \\
$\mathrm{Age} \geq 18$ y & $3 / 7(42.9 \%)$ & $2 / 6(33.3 \%)^{*}$ & \\
$90-\mathrm{d}$ & $9 / 23(39.1 \%)$ & $5 / 20(25.0 \%)$ & .3240 \\
$\mathrm{Age}<18$ y & $6 / 16(37.5 \%)$ & $2 / 14(14.3 \%) \dagger$ & \\
$\mathrm{Age} \geq 18$ y & $3 / 7(42.9 \%)$ & $3 / 6(50.0 \%) \dagger$ & \\
${ }^{*}$ Age $<18$ years vs age $\geq 18$ years; $P=.02 . \dagger$ Age $<18$ years vs age $\geq 18$ years; \\
$P=.09$.
\end{tabular}

10.8; 95\% CI, 1.5-75.7). Early mortality was lower among patients transplanted after 1999 (Table 4). A trend was seen toward a reduction in 30-day mortality among patients palliated with a Glenn procedure $(17.6 \%)$ compared with

TABLE 5. Mortality at 30, 60, and 90 days among patients with "failed Fontan" $(n=43)$

\begin{tabular}{lcccc}
\hline & & \multicolumn{3}{c}{ Mortality (\%) } \\
\cline { 3 - 6 } \multicolumn{1}{c}{ Variable } & Patients (n) & $\mathbf{3 0 ~ d}$ & $\mathbf{6 0 ~ d}$ & $\mathbf{9 0 ~ d}$ \\
\hline PLE & 15 & 14.3 & 14.3 & 35.7 \\
Acute failur e/postcardiotomy & 4 & 50.0 & 50.0 & 50.0 \\
$\quad$ shock & & & & \\
Chronic failure & 17 & 29.4 & 35.3 & 35.3 \\
Plastic bronchitis & 1 & 0.0 & 0.0 & 0.0 \\
Pulmonary AVMs & 3 & 0.0 & 0.0 & 0.0 \\
Classic & 22 & 22.7 & 27.3 & 31.8 \\
Extracardiac & 4 & 25.0 & 25.0 & 50.0 \\
Lateral tunnel & 11 & 27.27 & 27.3 & 36.4 \\
Take-down & 3 & 33.3 & 33.3 & 33.3 \\
\hline PLE, Prown
\end{tabular}

PLE, Protein-losing enteropathy; $A V M S$, arteriovenous malformations. 


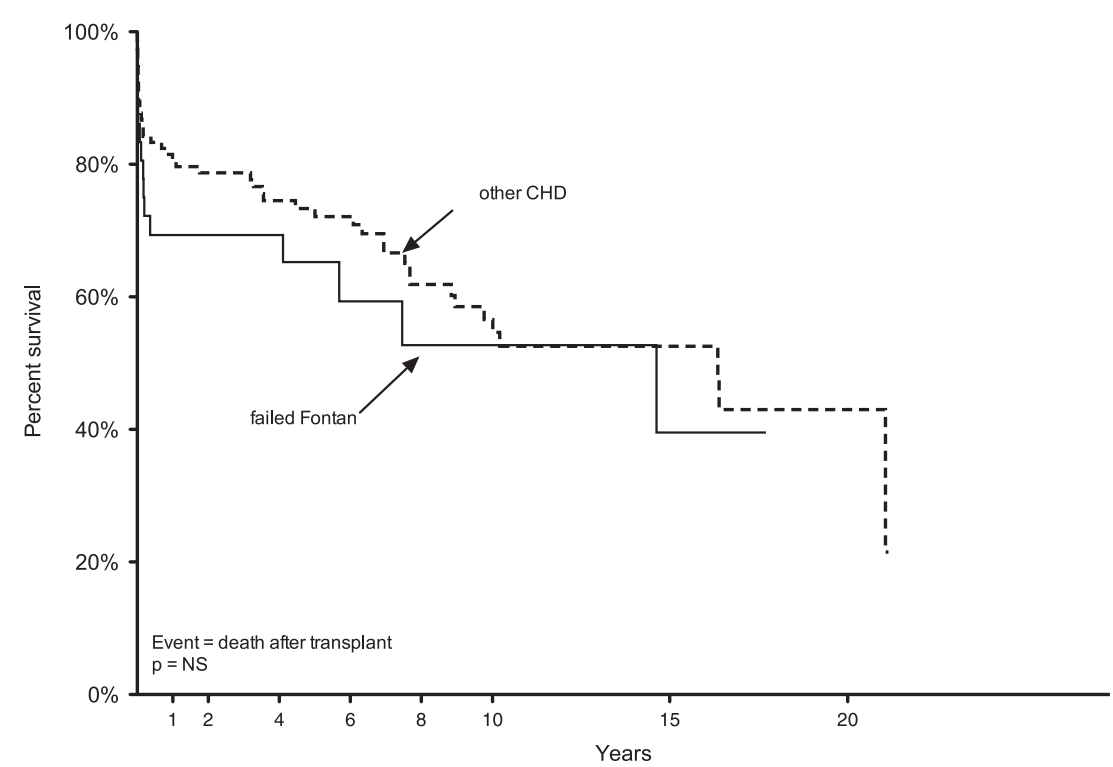

FIGURE 1. Fifteen-year Kaplan-Meier post-transplant survival estimates illustrated as a function of previous Fontan procedure among patients with a history of congenital heart disease $(C H D)(P=.12)$.

the single ventricle patients at all other stages (unpalliated, shunted, or Fontan; 28.6\%; OR, 0.54; 95\% CI, 0.17-1.68).

The elapsed time between the Fontan procedure and transplantation did not affect 30-day survival. Neither did the indication for transplantation, although the sample size limited the statistical analysis, but the patients transplanted for acute cardiac failure had poor outcomes (Table 5). Among the patients with PLE, a creatinine level greater than 1.5 was a predictor of 30-day mortality ( $100 \%$ vs $13.4 \%, P=.047)$; however, the presence of ascites (OR, 0.75; 95\% CI, 0.0511.6) or albumin less than 3.0 within 1 month of transplantation (OR, 0.24 ; $95 \% \mathrm{CI}, 0.02-3.01)$ were not.

\section{Late Post-Transplant Outcomes}

The long-term survival rate among the 43 patients with failed Fontan circulation was $62.4 \%$ at 1 year, $58.7 \%$ at 5 years, and $47.5 \%$ at 10 years. Although a trend was seen toward worse long-term survival among the Fontan patients, this mostly resulted from increased mortality within the first few months after transplantation. After the early postoperative period, the long-term risk of mortality was similar (Figure 1).

Among all patients with single-ventricle CHD, a trend was seen toward improved survival among patients transplanted after palliation with either a bidirectional or classic

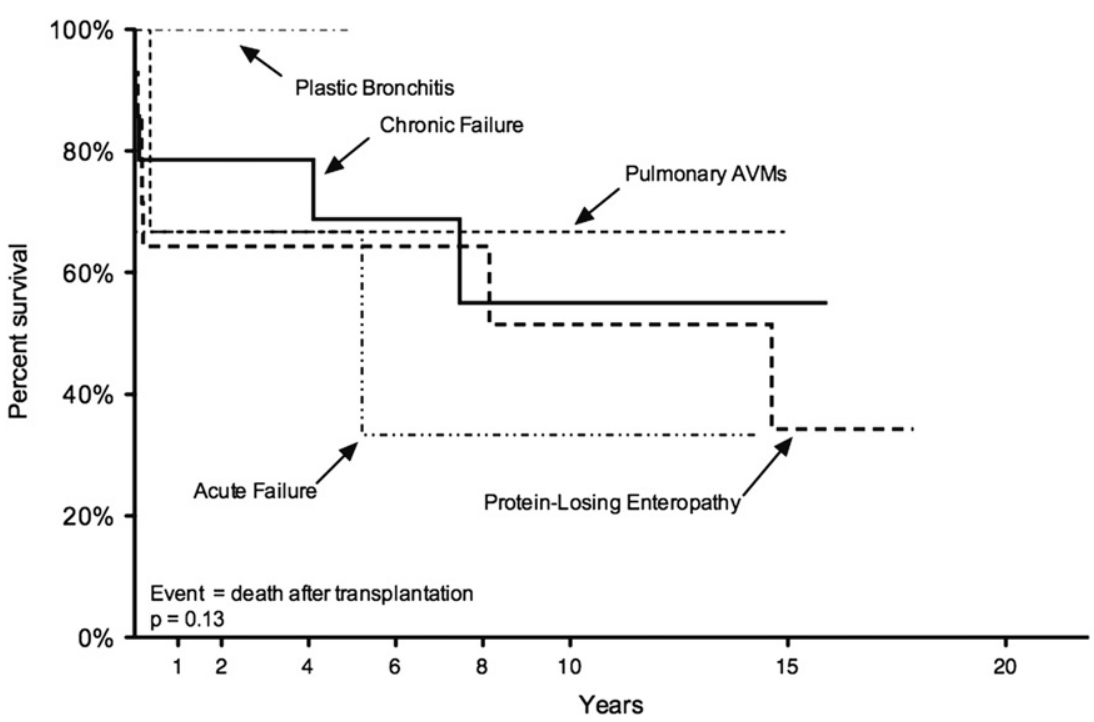

FIGURE 2. Fifteen-year Kaplan-Meier estimates of post-transplant survival stratified by the indication for transplantation among the 40 patients with "failed Fontan" circulation. AVM, Arteriovenous malformation. 


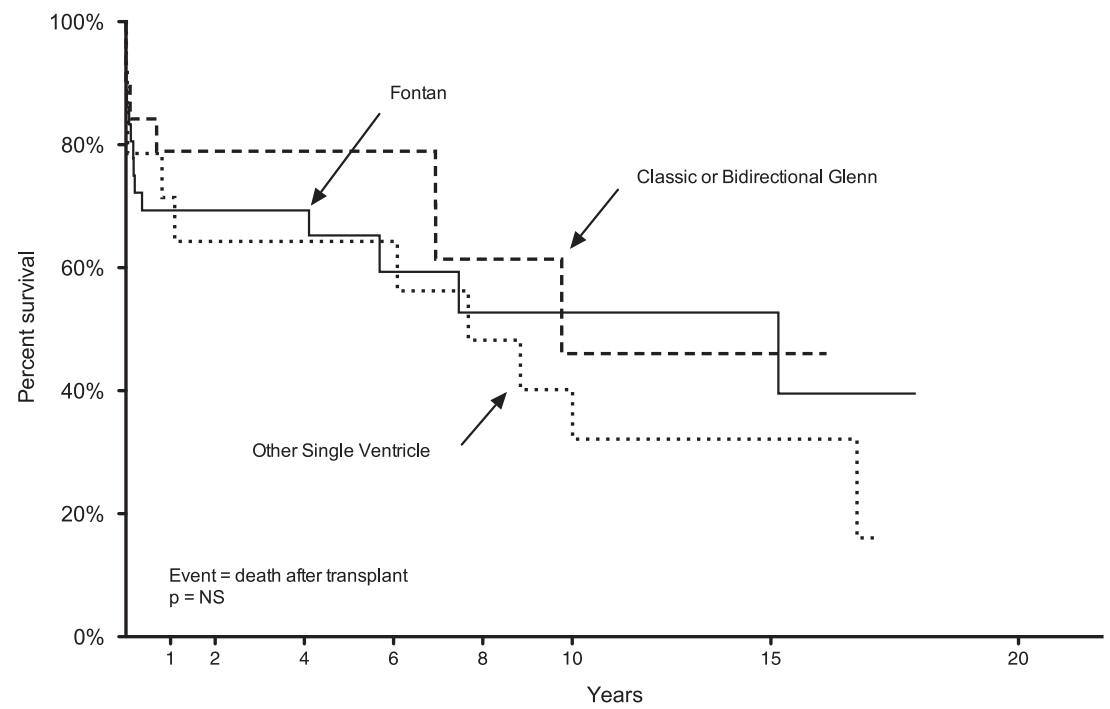

FIGURE 3. Fifteen-year Kaplan-Meier estimates of post-transplant survival among all patients transplanted with a single ventricle stratified by the type of previous surgical palliation performed $(P=\mathrm{NS})$.

Glenn procedure compared with those who did not make it to a Glenn procedure and those who underwent a Fontan procedure (Figure 3). Overall, the survival of patients with a single ventricle was lower than that for patients with 2 functional ventricles before transplantation $(P=.0321$; Figure 4$)$. The indication for transplantation did not predict long-term survival (Figure 2). Survival was also similar regardless of whether the patients had ascites at of transplantation.

Transplantation resulted in resolution of PLE in most long-term survivors. Data were not available for 2 patients, and 5 patients died before discharge. Of the remaining 9 patients, 1 did not have resolution of PLE, most likely secondary to complete occlusion of the central veins above the superior vena cava; 1 required 646 days to normalize his albumin level, but he also had a diagnosis of cirrhosis and hepatitis $\mathrm{C}$. The other 7 patients had normal albumin levels at a median of 44 days (range, $7-114$ ) after transplantation. Plastic bronchitis resolved, with normal bronchoscopy findings after transplantation; the pulmonary arteriovenous malformations also resolved, but took longer.

\section{Causes of Death Within Failed Fontan Group}

Three phases of mortality were observed. Within the first week, most patients who died did so of bleeding causes. Of the 8 deaths within 1 week of transplantation, 6 were

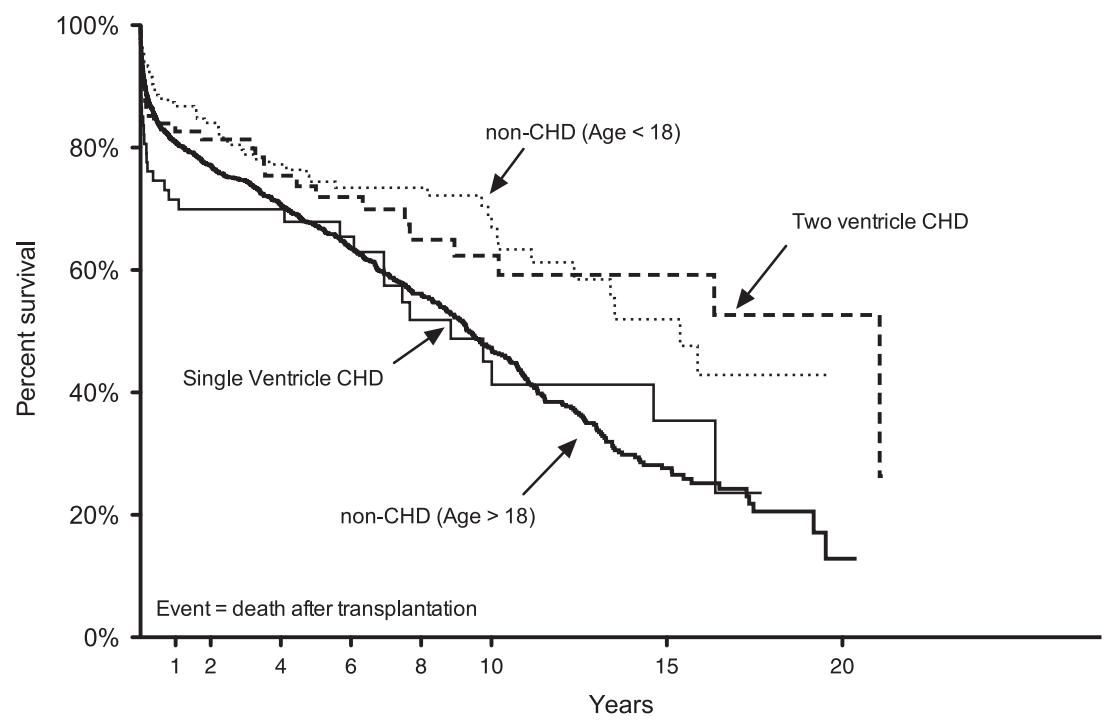

FIGURE 4. Fifteen-year Kaplan-Meier estimates of post-transplant survival among all patients undergoing transplantation from 1987 to 2004 . Stratified by presence or absence of congenital heart disease $(C H D)$, and number of functional ventricles before transplantation. 
secondary to bleeding, 1 was due to cardiovascular collapse after a prolonged period of cardiopulmonary bypass, and 1 was due to acute postoperative right ventricular failure. Since 1995, only 1 patient has died of intractable postoperative bleeding (Table 2). From 1 week to 3 months, most of the 5 deaths resulted from infectious complications $(\mathrm{n}=4$, $80 \%$ ); rejection was the primary cause of death for the remaining 5 patients.

The predictors of mortality within 7 days of transplantation included creatinine greater than $1.5(\mathrm{OR}, 14.0 ; 95 \% \mathrm{CI}$, $1.9-102.9)$ and the need for mechanical ventilation (OR, $5.5 ; 95 \%$ CI, 0.8-37.6).

\section{DISCUSSION}

Placement of the pulmonary circulation in series with the systemic circulation remains an elegant solution to the patient with CHD without a functional second ventricle. Recent series have demonstrated excellent early and late results after the Fontan procedure; however, even contemporary series have a persistent percentage of patients with Fontan failure. Technical issues and the timing of the Fontan procedure may play a role in some cases of failure; however, even the "perfect" Fontan procedure cannot provide a permanent solution for every patient. ${ }^{1,2}$

Although not addressed in the present study, many causes of Fontan failure are amenable to surgical or interventional correction, including atrial arrhythmia ablation, atrioventricular valve repair or replacement, and conduit revision. ${ }^{3,4}$ However, the results of surgical or catheter-based treatments of Fontan failure have often been poor-whether performed for PLE, arrhythmias, or progressive heart failure. $^{3,8-10}$ This has led many centers to undertake cardiac transplantation as a more definitive treatment of the failed Fontan procedure. ${ }^{11-14}$ At Columbia, we have used cardiac transplantation as the preferred treatment for Fontan failure in the absence of specific correctable anatomic issues. With the increasing prevalence of adults with CHD, the number of patients listed for cardiac transplantation with Fontan failure can also be expected to increase. $^{15}$

Unfortunately, few studies have systematically evaluated patients who have undergone transplantation after a failed Fontan procedure to assess their outcome compared with other patients with CHD, leaving clinicians largely in the dark about the expected outcomes after transplantation. In the present study, we report our single-institution experience with transplantation as treatment of the failing Fontan circulation.

The early mortality after transplantation was high but, consistent with our experience among all patients with CHD, recent survival has improved compared with earlier experience. ${ }^{16}$ Most notably, since 2000 , only a single patient has died of postoperative bleeding. The early experience included a significant learning curve with the methods of pulmonary artery reconstruction and reconstruction of the venous return, including the use of baffles to correct pulmonary venous return, as appropriate. The reduction in postoperative hemorrhagic deaths suggests that many of these technical hurdles have been overcome.

Despite these improvements, transplantation for the failing Fontan circulation remains a technically demanding surgery, frequently needing complex pulmonary artery reconstruction, long bypass times, and periods of deep hypothermic circulatory arrest. Increased experience with these technical aspects and the resultant decreases in operative times and technical complications likely played a role in the decreased incidence of bleeding and early postoperative death. Other possible contributors to the improvement in early outcomes include the increased use of antifibrinolytic agents, more careful patient selection (both transplantation of patients before the onset of end-organ-especially liver-failure and the refusal to transplant patients already in liver failure), and more meticulous attention to hemostasis with the recognition of the significant contribution of hemorrhage to early postoperative death.

Recent data from Kanter et $\mathrm{al}^{17}$ reports mortality among the Fontan patients that is equivalent to that among nonFontan transplantations (including, presumably, patients with cardiomyopathy). Although superficially at odds with our results, close inspection shows that the differences are mostly related to the patients included in the study; in our most recent era, we had no mortality within 30 days among the pediatric Fontan patients. Adult patients provide additional challenges, especially with regard to bleeding in patients with hepatic congestion and relative hepatic dysfunction. Evaluations of hepatic function are performed in all patients, although biopsy usually shows findings consistent with congestive heart failure. Most patients with a failing Fontan will have some degree of liver dysfunction and coagulopathy, but quantifying this dysfunction is helpful in planning the implantation procedure.

While mundane, it bears repeating that planning for sternal re-entry is a critical part of the procedure; cross-sectional imaging should be used as necessary to determine a safe reentry strategy in these patients where injury to the right atrium may quickly result in massive systemic air embolus.

The other critical technical aspect of the operation is reconstruction of the pulmonary arterial pathway. Although most reconstructions in our series were performed using donor tissue, other materials have also been used successfully. Therefore, waiting for the "perfect" donor from whom extensive donor tissue can be included as a part of the cardiectomy could needlessly prolong the waiting list time.

Close coordination between the donor and recipient surgeons during these procedures is essential, given the combination of multiple reoperative surgery, long travel times for retrieval of pediatric organs, and complex anatomic 
reconstruction during allograft implantation. Failure to allow for the recipient dissection time can result in the donor organ spending additional time on ice, compromising posttransplant cardiac function. We have demonstrated mean organ ischemic times of less than 5 hours, only 30 minutes longer than the patients in the congenital group.

Other investigators have suggested that, among single ventricle patients, transplantation might be best considered as an alternative to the Fontan procedure in high-risk patients, because patients transplanted after the Glenn procedure (before Fontan completion) - even in an earlier and smaller series from our own institution - had significantly better outcomes than those who first underwent a Fontan procedure. ${ }^{12,13}$ However, in the present larger series, we did not find a dramatic improvement in outcomes when transplantation occurred before Fontan completion, although a trend was seen toward improved results among patients with only a Glenn procedure. This might have been a result of random variation between the outcomes in groups with small sample sizes or of differences in patient selection across series. Alternatively, it might indicate the high morbidity level among patients with a Glenn procedure referred for transplantation in an era with excellent Fontan outcomes. ${ }^{18,19}$

The mean age at Fontan in these patients was older than 7 years, substantially older than in the typical Fontan series. This likely reflects the poorer results obtained with late Fontan palliation. ${ }^{19}$ Although most patients underwent transplant evaluation for single ventricle failure, other indications included PLE and acute failure after Fontan conversion. We did not identify any group of patients unlikely to benefit from transplantation (whether by diagnosis or by interval between the Fontan procedure and transplantation), although, clearly, patients with acute post-Fontan failure have high mortality rates even with transplantation.

Unlike other transplant candidates, elevated pulmonary vascular resistance is rarely a problem in the patients with failed Fontan circulation. Despite the often elevated pressures within the Fontan circuit, the transpulmonary gradients remained low in these patients. Accurate measurement of pulmonary vascular resistance in patients with Fontan circulation is largely precluded by the presence of significant aortopulmonary collaterals. We have traditionally thought that any increase in pulmonary vascular resistance tolerated by Fontan patients-living without a pulmonary ventricle-would be too small to pose a risk to a healthy donor right ventricle. However, we speculate that accurate measurements of pulmonary vascular resistance might demonstrate some patients in whom transplantation would be less likely to be successful, given that at least 1 patient died after right ventricular failure during allograft implantation.

Management of the aortopulmonary collaterals in the pre- and post-transplant period remains challenging. Although coiling might enable more accurate determination of pulmonary vascular resistance, most of these patients are cyanotic and loss of this pulmonary blood flow would likely result in worsening hypoxia. In patients with signficant collaterals, this may necessitate alterations in the cardiopulmonary bypass stratgey with periods of low flow or circulatory arrest to minimize pulmonary venous return. However, in the post-transplant period we have a low threshhold for returning to the catheterization laboratory for percutaneous closure of remaining collaterals, especially in patients showing evidence of high cardiac output.

Consistent with other reports, patients with PLE did not have greater mortality (even in the presence of ascites), and resolution of PLE in the post-transplant period was common. ${ }^{14}$ Other treatments for PLE have yielded inconsistent results, and the mortality rate at 5 years can exceed $50 \% \cdot{ }^{8,20}$ In the absence of clear and well-defined hemodynamic problems amenable to correction, transplantation offers the best opportunity for treatment of PLE in patients with Fontan circulation. Patients with pulmonary arteriovenous malformations and plastic bronchitis also had similar post-transplant outcomes, suggesting that these patients might benefit significantly from early transplantation, although resolution of arteriovenous malfomations may take several months.

The optimal timing of transplantation in patients with a failing Fontan circulation remains problematic. Overall, the tendency has been to list patients for transplantation earlier in more recent eras (this may be a signficant contributor to improved outcomes). In that way, we are able to transplant patients with only a failing Fontan, not a failing Fon$\tan$ with bad ventricular function, poor nutrition, and marginal renal function.

Although the onset of PLE or ascites did not increase post-transplant mortality, other clinical parameters did. Despite the small sample size, it was clear that once patients had developed renal dysfunction, survival after transplantation was markedly decreased. Although preoperative renal failure is a predictor of poor outcomes in all patients undergoing heart transplantation, patients with 2 ventricles might be easier to bridge to transplantation while optimizing endorgan perfusion. ${ }^{21}$ Single ventricle physiology makes the use of ventricular assist devices (for both ventricular unloading and optimization of perfusion) difficult, and the poor results suggest that extracorporeal membrane oxygenation is not a preferred alternative as a bridge to transplantation. ${ }^{21}$ Worsening renal function, where it is thought to be due to low-cardiac output and possibly reversible, might be considered an indication for acceleration of listing and earlier transplantation before the development of complete renal failure.

This suggests that patients with failing Fontan circulation should be evaluated early for transplantation, and transplantation should be performed before Fontan failure, resulting in significant systemic hypoperfusion. Griffiths et $\mathrm{al}^{22}$ have 
identified preserved ventricular function as a significant risk factor for mortality independent of transplantation, reinforcing the need to improve our ability to identify irreversible Fontan failure in this complicated population and offer transplantation at an earlier timepoint. Pretransplantation management should focus on optimizing nutritional and functional status. We have a low threshhold for admitting patients with a failing Fontan (especially those with PLE) for therapy including diuretics, inotropes, and therapeutic paracentesis. Low-dose inotropes may be helpful, even among patients with only mild ventricular dysfunction but with failing Fontan circulation.

\section{Study Limitations}

Although this is the largest single-institution series to date, the small sample size remains a significant limitation in any analysis of transplantation for the failing Fontan circulation because it limits the ability to perform multivariate analysis. Even with univariate analysis, to have a $90 \%$ chance of detecting a twofold increase in mortality from $15 \%$ to $30 \%$, a sample of 162 patients would have been required. However, patients with failing Fontan circulation (especially when they undergo transplantation in adulthood), might not be accurately captured in any existing database, leaving small single-institution studies such as ours the only method for examining the outcomes in these patients. In addition, to maximize the number of patients we examined, it was necessary to include a long period in the analysis, and peritransplant management has changed significantly from 1984 to 2007 (as evidenced by the reduced mortality rates after the more recent transplants).

\section{CONCLUSIONS}

Despite these limitations, these data support several conclusions. First, early mortality after transplantation for the failing Fontan circulation is greater than among patients with CHD and 2 functional ventricles. The improving results during the past 2 decades reinforce the need to refer these patients to centers with experience in transplantation involving complex congenital disease; however, the perioperative mortality remains high and consideration of the use of alternate listing strategies for these patients might enable maximization of the limited supply of donor allografts. Second, the results in the most recent decade have improved, and we could not identify any patients with failed Fontan circulation not amenable to transplantation in the current era. Third, the indicators of clinical status at transplantation, including renal failure, rather than the specific diagnosis or indication for transplantation, were the strongest predictors of poor survival. Finally, perhaps the most important lesson is that early referral for transplantation-before the development of nutritional debilitation, cachexia, and even subtle end-organ injury-is crucial to optimizing post-transplant outcomes among patients with a failing Fontan.

\section{References}

1. Fontan F, Kirklin JW, Fernandez G, Costa F, Naftel DC, Tritto F, et al. Outcome after a "perfect" Fontan operation. Circulation. 1990;81:1520-36.

2. Hosein RB, Clarke AJ, McGuirk SP, Griselli M, Stumper O, De Giovanni JV, et al. Factors influencing early and late outcome following the Fontan procedure in the current era: the "two commandments"? Eur J Cardiothorac Surg. 2007; 31:344-53.

3. Marcelletti CF, Hanley FL, Mavroudis C, McElhinney DB, Abella RF, Marianeschi SM, et al. Revision of previous Fontan connections to total extracardiac cavopulmonary anastomosis: a multicenter experience. J Thorac Cardiovasc Surg. 2000;119:340-6.

4. Mavroudis C, Backer CL, Deal BJ, Johnsrude C, Strasburger J. Total cavopulmonary conversion and maze procedure for patients with failure of the Fontan operation. J Thorac Cardiovasc Surg. 2001;122:863-71.

5. Lower RR, Shumway NE. Studies on orthotopic homotransplantation of the canine heart. Surg Forum. 1960;11:18-9.

6. Davies RR, Russo MJ, Sorabella RA, Gelijns AC, Mosckowitz AJ, Naka Y, et al. Cardiac transplant anastomosis and the need for permanent pacemaker implantation: an analysis of the United Network for Organ Sharing database. J Heart Lung Transpl. 2008;27:S136.

7. Sievers HH, Weyand M, Kraatz EG, Bernhard A. An alternative technique for orthotopic cardiac transplantation, with preservation of the normal anatomy of the right atrium. Thorac Cardiovasc Surg. 1991;39:70-2.

8. Mertens L, Hagler DJ, Sauer U, Somerville J, Gewillig M, PLE Study Group. Protein-losing enteropathy after the Fontan operation: an international multicenter study. J Thorac Cardiovasc Surg. 1998;115:1063-73.

9. Weipert J, Noebauer C, Schreiber C, Kostolny M, Zrenner B, Wacker A, et al. Occurrence and management of atrial arrhythmia after long-term Fontan circulation. J Thorac Cardiovasc Surg. 2004;127:457-64.

10. Rychik J. Protein-losing enteropathy after Fontan operation. Congenital Heart Dis. 2007;2:288-300.

11. Bernstein D, Naftel D, Chin C, Addonizio LJ, Gamberg P, Blume ED, et al. Outcome of listing for cardiac transplantation for failed Fontan: a multi-institutional study. Circulation. 2006;114:273-80.

12. Jayakumar KA, Addonizio LJ, Kichuk-Chrisant MR, Galantowicz ME, Lamour JM, Quaegebeur JM, et al. Cardiac transplantation after the Fontan or Glenn procedure. J Am Coll Cardiol. 2004;44:2065-72.

13. Michielon G, Parisi F, Squitieri C, Carotti A, Gagliardi G, Pasquini L, et al. Orthotopic heart transplantation for congenital heart disease: an alternative for high-risk Fontan candidates? Circulation. 2003;108(Suppl 1):II140-9.

14. Gamba A, Merlo M, Fiocchi R, Terzi A, Mammana C, Sebastiani R, et al. Heart transplantation in patients with previous Fontan operations. J Thorac Cardiovasc Surg. 2004; 127:555-62.

15. Warnes CA, Liberthson R, Danielson GK, Dore A, Harris L, Hoffman JIE, et al. Task force 1: the changing profile of congenital heart disease in adult life. J Am Coll Cardiol. 2001;37:1170-5.

16. Chen JM, Davies RR, Mital SR, Mercando ML, Addonizio LJ, Pinney SP, et al. Trends and outcomes in transplantation for complex congenital heart disease: 1984 to 2004. Ann Thorac Surg. 2004;78:1352-61.

17. Kanter KR, Mahle WT, Vincent RN, Berg AM, Kogon BE, Kirshbom PM. Heart transplantation in children with a Fontan procedure. Ann Thorac Surg. 2011;91: 823-30.

18. Hsu DT, Quaegebeur JM, Ing FF, Selber EJ, Lamour JM, Gersony WM. Outcome after the single-stage, nonfenestrated Fontan procedure. Circulation. 1997;96: II-335-40.

19. Stamm C, Friehs I, Mayer JE, Zurakowski D, Triedman JK, Moran AM, et al. Long-term results of the lateral tunnel Fontan operation. J Thorac Cardiovasc Surg. 2001;121:28-41.

20. Ghanayem NS, Berger S, Tweddell JS. Medical management of the failing Fontan. Pediatr Cardiol. 2007;28:465-71.

21. Davies RR, Russo MJ, Mital S, Martens TM, Sorabella RS, Hong KN, et al. Predicting survival among high-risk pediatric cardiac transplant recipients: an analysis of the United Network for Organ Sharing database. J Thorac Cardiovasc Surg. 2008;135:147-55. 155.e1-2.

22. Griffiths ER, Kaza AK, Wyler von Ballmoos MC, Loyola H, Valente AM, Blume ED, et al. Evaluating failing Fontans for heart transplantation: predictors of death. Ann Thorac Surg. 2009;88:558-64. 
TABLE E1. Operative details for patients undergoing transplantation for failed Fontan $(n=43)$

\begin{tabular}{|c|c|c|c|c|c|}
\hline Pt. no. & CPB time & TCA time & Ischemic time & Anastomosis & Complex reconstruction \\
\hline 39 & 134 & 0 & 109 & Biatrial & None \\
\hline 49 & 249 & 0 & 228 & Biatrial & Donor PA used to reconstruct recipient pulmonary artery bifurcation \\
\hline 53 & 289 & 0 & 253 & Biatrial & Donor PA used to reconstruct recipient pulmonary artery bifurcation \\
\hline 69 & 377 & 0 & 397 & Biatrial & 10-mm Dacron graft used to replace R PA \\
\hline 73 & 286 & 54 & 281 & Biatrial & $\begin{array}{l}\text { Donor PA used to reconstruct recipient pulmonary artery bifurcation } \\
\text { Donor SVC used to reconstruct recipient SVC }\end{array}$ \\
\hline 81 & 147 & 0 & 152 & Biatrial & Donor PA used to reconstruct recipient pulmonary artery bifurcation \\
\hline 82 & 183 & 0 & 192 & Biatrial & Pericardial patch to reconstruct R PA \\
\hline 83 & 311 & 1 & 339 & Biatrial & None \\
\hline 787 & 420 & 0 & 360 & Bicaval & 12-mm PTFE graft used to replace R PA \\
\hline 790 & 426 & 61 & 327 & Bicaval & 12-mm PTFE used to replace R and L PAs \\
\hline 87 & 247 & 65 & 193 & Bicaval & Donor PA used to reconstruct recipient pulmonary artery bifurcation \\
\hline 791 & 369 & 0 & 172 & Biatrial & Interatrial baffle to direct L SVC and L IVC to R side (situs inversus) \\
\hline 91 & 292 & 48 & 331 & Biatrial & $\begin{array}{l}\text { Donor PA used to reconstruct recipient pulmonary artery bifurcation } \\
\text { Recipient coronary sinus L in situ to drain L SVC }\end{array}$ \\
\hline 98 & 253 & 0 & 270 & Biatrial & Donor PA used to reconstruct recipient pulmonary artery bifurcation \\
\hline 99 & 309 & 0 & 151 & Bicaval & Autologous pericardium to reconstruct R PA \\
\hline 379 & 487 & 50 & 292 & Bicaval & 12-mm PTFE used to replace R and L PAs \\
\hline 794 & 274 & 80 & 220 & Biatrial & None \\
\hline 105 & 240 & 0 & 220 & Biatrial & Donor PA used to reconstruct recipient $\mathrm{R} P A$ \\
\hline 113 & 188 & 0 & 239 & Bicaval & Patch used to reconstruct R PA \\
\hline 115 & 205 & 0 & 190 & Bicaval & None \\
\hline 145 & 330 & 0 & 343 & Bicaval & Donor PA used to reconstruct recipient pulmonary artery bifurcation \\
\hline 155 & 318 & 0 & 443 & Biatrial & Donor PA used to reconstruct recipient pulmonary artery bifurcation \\
\hline 801 & & 0 & & Bicaval & $\begin{array}{l}\text { Donor PA used to reconstruct recipient pulmonary artery bifurcation } \\
\text { Bovine pericardial baffle used to connect L and R SVCs }\end{array}$ \\
\hline 171 & 243 & 0 & 330 & Bicaval & Donor PA used to reconstruct recipient pulmonary artery bifurcation \\
\hline 198 & & 0 & 202 & Bicaval & $\begin{array}{l}\text { Donor PA used to reconstruct recipient pulmonary artery bifurcation and } \\
\text { R PA }\end{array}$ \\
\hline 203 & 173 & 0 & 160 & Bicaval & Pulmonary homograft used to reconstruct R and L PAs \\
\hline 204 & 210 & 0 & 267 & Bicaval & None \\
\hline 205 & 198 & 0 & 233 & Bicaval & Donor PA used to reconstruct recipient $\mathrm{R}$ and $\mathrm{L}$ PAs \\
\hline 207 & 175 & 0 & 220 & Bicaval & Transplant to single R lung, baffled PA anastomosis \\
\hline 234 & 191 & 18 & 306 & Bicaval & $\begin{array}{l}\text { Donor PA used to reconstruct recipient pulmonary artery bifurcation } \\
\text { L SVC anastomosed to donor innominate vein } \\
\text { Hemiarch replacement performed for transverse aortic arch stenosis }\end{array}$ \\
\hline 768 & 234 & 0 & & Bicaval & Donor PA used to reconstruct recipient pulmonary artery bifurcation \\
\hline 248 & 234 & 0 & 164 & Bicaval & $\begin{array}{l}\text { Donor PA used to replace bifurcation and R PA } \\
\text { Donor PA used to reconstruct anterior SVC }\end{array}$ \\
\hline 249 & 351 & 0 & 285 & Bicaval & $\begin{array}{l}\text { Donor/recipient atrial tissue to baffle anomalous pulmonary venous } \\
\text { return from R to L atrium } \\
\text { Donor PA anastomosis made to previous Gore-Tex tube graft } \\
\text { replacement of bilateral pulmonary arteries } \\
\text { L SVC anastomosed to donor innominate vein } \\
\text { R SVC of negligible size, oversewn }\end{array}$ \\
\hline 251 & 326 & 39 & 399 & Bicaval & Site of previous Glenn shunt on R PA replaced with bovine pericardium \\
\hline 258 & 321 & 10 & 362 & Bicaval & $\begin{array}{l}\text { L SVC thromboembolectomy } \\
\text { L SVC anastomosed to donor innominate vein } \\
\text { Donor PA used to reconstruct R and L PAs } \\
\text { Patch angioplasty of R SVC using donor aorta }\end{array}$ \\
\hline 261 & 314 & 0 & & Bicaval & $\begin{array}{l}\text { Recipient } \mathrm{R} \text { atrial tissue and donor PA used to replace pulmonary artery } \\
\text { bifurcation }\end{array}$ \\
\hline 510 & 322 & 120 & 205 & Bicaval & $\begin{array}{l}\text { L SVC anastomosed to donor innominate vein } \\
\text { Donor PA used to reconstruct pulmonary artery bifurcation }\end{array}$ \\
\hline
\end{tabular}


TABLE E1. Continued

\begin{tabular}{|c|c|c|c|c|c|}
\hline Pt. no. & CPB time & TCA time & Ischemic time & Anastomosis & Complex reconstruction \\
\hline \multirow[t]{2}{*}{726} & 244 & & 238 & Bicaval & L SVC of negligible size, oversewn \\
\hline & & & & & Donor PA used to reconstruct $\mathrm{R}$ and $\mathrm{L}$ PAs \\
\hline \multirow[t]{2}{*}{740} & 376 & 64 & 294 & Bicaval & Bovine pericardial patch angioplasty of R PA \\
\hline & & & & & Pulmonary homograft reconstruction of anterior of $\mathrm{L}$ and $\mathrm{R}$ PA \\
\hline \multirow[t]{3}{*}{772} & 277 & 0 & 338 & Bicaval & Unifocalization of branch pulmonary arteries \\
\hline & & & & & Patch angioplasty of R PA using recipient atrium \\
\hline & & & & & Donor PA used to reconstruct anterior of pulmonary artery bifurcation \\
\hline 757 & 480 & 54 & 275 & Biatrial & Donor PA onlay patch angioplasty of pulmonary artery bifurcation \\
\hline 844 & 171 & 0 & 194 & Bicaval & Patch angioplasty of R PA using bovine pericardium \\
\hline 866 & 176 & 0 & 133 & Bicaval & Patch angioplasty of R PA using donor $\mathrm{L}$ atrial tissue \\
\hline
\end{tabular}

Pt. no., Patient number; $C P B$, cardiopulmonary bypass; $T C A$, total circulatory arrest; $P A$, pulmonary artery; $R$, right; $S V C$, superior vena cava; $P T F E$, polytetrafluoroethylene; $L$, left; $I V C$, inferior vena cava. 
TABLE E2. Incidence of neurologic events for patients undergoing transplantation for failed Fontan $(n=4)$

\begin{tabular}{|c|c|c|c|c|c|c|}
\hline Variable & Pt. no. & Year & TCA (min) & Clinical course & Brain imaging & Clinical outcome \\
\hline \multicolumn{7}{|l|}{ Stroke } \\
\hline & 82 & 1992 & None & $\begin{array}{l}\text { On ECMO before transplantation; } \\
\text { neurologic status not clear } \\
\text { immediately before } \\
\text { transplantation; re-explored for } \\
\text { bleeding; died POD } 1 \text { of } \\
\text { intractable bleeding }\end{array}$ & None & Died POD 1 \\
\hline & 91 & 1994 & 49 & $\begin{array}{l}\text { POD } 4 \text { with cardiac arrest, } \\
\text { subsequently with decreased } \\
\text { right-sided movement }\end{array}$ & $\begin{array}{l}\text { MRI, subcortical lesions c/w } \\
\text { hypotensive episode }\end{array}$ & $\begin{array}{l}\text { Mild decrease in RUE strength at } \\
\text { discharge; alive }\end{array}$ \\
\hline & 99 & 1994 & None & $\begin{array}{l}\text { Extubated POD } 2 \text { but subsequent } \\
\text { course complicated by } \\
\text { multiorgan system failure and } \\
\text { cardiac arrest; POD } 30 \text { with } \\
\text { symmetric strength, but then } \\
\text { with cardiac arrest and then } \\
\text { bihemispheric stroke }\end{array}$ & $\begin{array}{l}\text { EEG consistent with severe } \\
\text { bihemispheric injury }\end{array}$ & Died POD 40 \\
\hline & 113 & 1995 & None & $\begin{array}{l}\text { No intraoperative issues; multiple } \\
\text { seizures in postoperative period }\end{array}$ & $\begin{array}{l}\text { CT, bihemispheric small infarcts, } \\
\text { L frontal, R occipital/parietal, } \\
\text { old pontine lesions c/w } \\
\text { watershed infarcts }\end{array}$ & $\begin{array}{l}\text { Walking with assistance, speaking } \\
\text { sentences, severe cognitive } \\
\text { deficits; died } 6 \text { yr after } \\
\text { transplant }\end{array}$ \\
\hline & 772 & 2006 & None & $\begin{array}{l}\text { Required re-exploration for } \\
\text { bleeding on POD 1, factor } 7 \\
\text { given, systolic blood pressure } \\
\text { in } 80 \text { s; L upper extremity } \\
\text { weakness noted POD } 1\end{array}$ & $\begin{array}{l}\mathrm{CT}, \mathrm{R} \text { frontal subcortical infarct, } \\
\text { no hemorrhage }\end{array}$ & $\begin{array}{l}\text { Still with decreased strength and } \\
\text { numbness in LUE/LLE; alive }\end{array}$ \\
\hline & 234 & 2004 & 18 & $\begin{array}{l}\text { POD } 16 \text {, seizures and later facial } \\
\text { weakness, small acute bleeding } \\
\text { site on imaging }\end{array}$ & $\begin{array}{l}\text { CT/MRI, multiple regions of } \\
\text { arterial stenoses/dilations, tight } \\
\text { vertebral artery stenosis, } \\
\text { impaired cerebral perfusion; } \\
\text { likely old caudate infarct with } \\
\text { post-transplant bleed }\end{array}$ & $\begin{array}{l}\text { Facial weakness resolved before } \\
\text { discharge; no sequelae; alive }\end{array}$ \\
\hline \multicolumn{7}{|l|}{ Subdural } \\
\hline & 510 & 2006 & 120 & POD 3 with right-sided weakness & $\begin{array}{l}\text { CT/MRI, small subdural } \\
\text { hematoma, no evidence of } \\
\text { stroke }\end{array}$ & $\begin{array}{l}\text { No deficits on neurologic } \\
\text { examination at discharge; alive }\end{array}$ \\
\hline \multicolumn{7}{|l|}{ Seizure } \\
\hline & 768 & 2004 & None & $\begin{array}{l}\text { Intraoperative course with severe } \\
\text { protamine reaction; } \\
\text { postoperative course } \\
\text { complicated by vasodilatory } \\
\text { shock, renal failure, } \\
\text { pneumonia; } 2 \text { complex partial } \\
\text { seizures treated with Keppra }\end{array}$ & $\begin{array}{l}\text { CT, no infarct, hemorrhage, mass } \\
\text { effect }\end{array}$ & No neurologic sequelae; alive \\
\hline
\end{tabular}

Pt. no., Patient number, TCA, total circulatory arrest; $E C M O$, extracorporeal membrane oxygenation; $P O D$, postoperative day; $R$, right; $M R I$, magnetic resonance imaging; $R U E$, right upper extremity; $E E G$, electroencephalogram; $C T$, computed tomography; $L$, left; $L U E$, left upper extremity; $L L E$, left lower extremity. 
TABLE E3. Clinical course of 5 patients requiring post-transplant dialysis

\begin{tabular}{|c|c|c|c|c|c|}
\hline Pt. no. & Age (yr) & Year & Postoperative clinical course & Preoperative clinical status & Outcome \\
\hline 99 & 13 & 1994 & $\begin{array}{l}\text { CVVH } \times 1 \mathrm{~d} \text { in setting of cardiopulmonary } \\
\text { arrest and sepsis }\end{array}$ & Normal renal function & Died POD 40 \\
\hline 82 & 3 & 1992 & $\begin{array}{l}\text { Immediate postoperative course required } \\
\text { re-exploration for bleeding, profound } \\
\text { hypotension }\end{array}$ & $\begin{array}{l}\text { On ECMO with renal failure, dialysis } \\
\text { initiated before ECMO }\end{array}$ & Died POD 1 \\
\hline 249 & 13 & 2005 & $\begin{array}{l}\text { Postoperative course complicated by sepsis, } \\
\text { including aspergillosis, CVVH initiated on } \\
\text { day of death }\end{array}$ & Normal renal function & Died POD 60 \\
\hline 251 & 20 & 2005 & $\begin{array}{l}\text { Patient received hemodialysis } \\
\text { intraoperatively for intractable } \\
\text { hyperkalemia; could not be resuscitated }\end{array}$ & Normal renal function & Died POD 0 in OR \\
\hline 261 & 22 & 2005 & $\begin{array}{l}\text { Complicated postoperative course with sepsis } \\
\text { and multiorgan system failure, } \mathrm{CVVH} \\
\text { required intermittently until death }\end{array}$ & Normal renal function & Died POD 63 \\
\hline
\end{tabular}

Pt. no., Patient number; $C V V H$, continuous venovenous hemofiltration; $P O D$, postoperative day; $E C M O$, extracorporeal membrane oxygenation; $O R$, operating room. 